
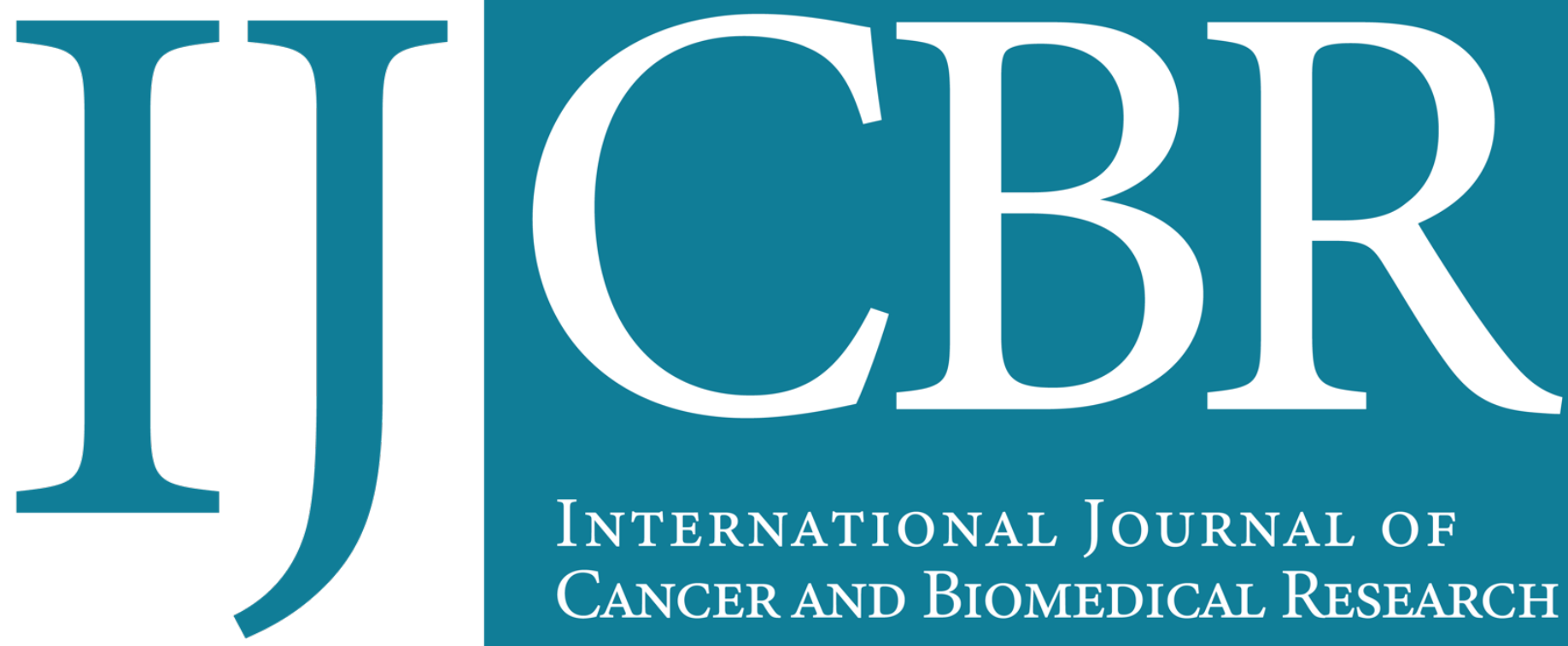

INTERNATIONAL JOURNAL OF CANCER AND BIOMEDICAL RESEARCH

https://jcbr.journals.ekb.eg

Editor-in-chief

Prof. Mohamed Labib Salem, PhD

Intake of $\mathbf{\omega}-3$ fatty acids reduces obesity in mice through augmentation of lipid oxidation and thyroid signaling, and prevention of anemia

Maha A. El-Sayed, Mohamed M. Nasef, Yousry El-Bolkiny and Ibrahim K. El-Shourbagy 


\title{
Intake of $\omega-3$ fatty acids reduces obesity in mice through augmentation of lipid oxidation and thyroid signaling, and prevention of anemia
}

\author{
Yousry El-Bolkiny, Mohamed M. Nasef, Maha A. El-Sayed and Ibrahim K. El-Shourbagy \\ Zoology Department, Faculty of Science, Tanta University, Tanta, Egypt
}

\section{ABSTRACT}

Background: $\omega-3$ fatty acids in seafood, fatty fish, and supplements have health benefits as their variable physiological benefits. Aims: This study aimed to investigate the effects of different doses of $\omega-3$ fatty acids on body weight, levels of thyroid hormones, lipid components, oxidative markers and complete blood count (CBC). Materials and Methods: Mice $(n=160)$ were divided into 8 groups for short and long treatments. Results: Data showed that oral treatment reduced the body weight of mice organs in a dose and time-dependent manner. The treatments also reduced serum cholesterol and triglycerides levels as well as GSH. In contrast, the treatment increased the serum levels of anti-oxidants such as GPx, SOD and MDA. Meanwhile, the treatments increased significantly the serum levels of both $T_{3} \& T_{4}$ and decreased the pituitary TSH. The treatment also increased RBCs and platelet counts, as well as the hemoglobin concentration. All recorded effects of $\omega-3$ fatty acids were in a dose and time-dependent manner. Conclusion: Intake of $\omega-3$ fatty acids decreases obesity and amends animea through reducing increasing oxidative stress and enhancing RBCs and hemoglobin biosynthesis.

Keywords: $\omega 3$ fatty acids; body weight; CBC, lipids profile; antioxidants; thyroid hormones.

Editor-in-Chief: Prof. M.L. Salem, PhD - Article DOl: 10.21608/jcbr.2021.55216.1106
AII ARTICLE INFO

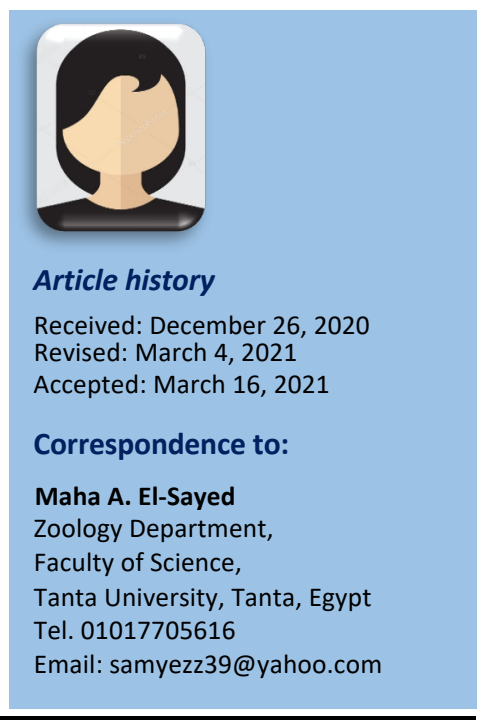

\section{INTRODUCTION}

The role of the diet in an organism's health remains controversial. The contribution to human health of the specific polyunsaturated fatty acids (PUFAs) has received considerable attention in the literature. PUFAs, in particular, $\omega-3$ fatty acids are key nutrients that affect early growth and development as well as the prevention of chronic diseases in later life (Burlingame et al., 2009). $\omega-3$ fatty acids are essential fatty acids that cannot be synthesized by mammals . Therefore, they must be obtained through the diet (Bousquet et al., 2008). Longchain $\omega-3$ fatty acids such as eicosapentaenoic (EPA) and docosahexaenoic acid (DHA) constitute the major part $(60 \%)$ of $\omega-3$ fatty acids. The major dietary sources for $\omega-3$ fatty acid derivatives are cold-water fish oil of salmon, herring, mackerel, anchovies and sardines. $\omega-3$ fatty acid can also be obtained from certain seeds such as flax and walnuts (Bolles and Begg, 2000).
At present, fish oil is gaining attention as an important source of natural and potential pharmaceuticals (Kaur et al., 2014).

As fish oil is most widely used as a food supplement owing to its wide array of biological activities, public and scientific interests have been directed toward its role in health promotion and disease prevention. Dietary fish oil containing $\omega-3$ PUFA, which possess beneficial effects to some chronic diseases such as cardiovascular, rheumatoid arthritis, diabetes, autoimmune, and cancer (Calder, 2007; Chapkin et al., 2009; Car and Webel, 2012; Cockbain et al., 2012; Miles and Calder, 2012; Xin et al., 2012; Vaughan et al., 2013). Other benefits such as a healthy brain, joint movement, balanced mood, strength, antiinflammatory, and normalization of triglycerides and cholesterol levels are shown in the literature. On the other side, oxidative stress is defined as an imbalance between the production and collection of reactive oxygen 
species (ROS). There is significant evidence that fish oil supplementation is beneficial in diseases with ROS imbalance, such as cancer and arrhythmia. It is cleared that the health and beneficial effects of fish oil seem to be due to its high content of $\omega-3$ fatty acids including DHA and EPA (Chapkin et al., 2009).

Scientific evidence revealed that a diet rich in long-chain $\omega-3$ fatty acids help in the development of a healthy brain, heart and immune system. It has a role in joint movement, balanced mood, a sense of well-being, strength, stamina and maintaining cholesterol levels within the normal range. Many studies suggest that $\omega-3$ fatty acids as diet-dependent factors may be critical to preventing disease backed up with physiological, anti-inflammatory and anticancer actions. The $\omega-3$ fatty acids can reduce circulating triglyceride concentrations, cholesterol accumulation in the aortic wall as well as lipid content in the liver and visceral adipose tissue, which are independent risk factors for atherosclerotic cardiovascular disease (CVD) (Cockbain et al., 2012; Vaughan et al., 2013).

The ability of $\omega-3$ fatty acids from fish oil (FO) to increase TRb1 gene expression in animals received a diet rich in FO from lactation to adult age. Concomitantly, those animals presented an increase in the activity of a mitochondrial glycerophosphate dehydrogenase, a classical target of thyrotrophic hormone (TH) of hypolipidemic action. It can be postulated that $\mathrm{TH}$ signaling is another route that could contribute to the actions of $\omega-3$ fatty acids (Souza et al., 2010; 2011) to reduce obesity.

Accordingly, we hypothesized that oral administration of $\omega-3$ fatty acids may affect or modulate the body and organ's weight, thyroid functions as well as $C B C$ and hemoglobin synthesis. This in vivo approach elucidates the interactions between $\omega-3$ fatty acids, CBC, lipid profile and oxidases from one side and the thyroid signaling from the other side. Therefore, the present work was assumed to investigate the effects of $\omega-3$ fatty acids on obesity-related indices and other health important functions such as CBC, lipid profile components, antioxidants and thyroid functions over two-time intervals; short and long treatments in the endogenous micro-environment of mice.

\section{MATERIAL AND METHODS}

\section{Animals}

One hundred sixty male Swiss albino mice (CD1 strain), 6-8 weeks old, weighing $22.0 \pm 2.0 \mathrm{~g}$ were purchased from Theodor Bilharz Research Institute (TBRI), Cairo, Egypt. Mice were acclimatized to the laboratory conditions for one week prior to the initiation of the experimental work. Mice were housed in standard plastic cages and maintained under controlled laboratory conditions of relative humidity $(55 \pm 5 \%)$, the temperature at $23 \pm 2^{\circ} \mathrm{C}$ and were exposed to a 12:12h light: dark cycle. Mice were provided with a standard pellet diet and tap water ad libitum under hygienic conditions in specific pathogen-free conditions complied with the National Institutes of Health guidelines for the care and use of laboratory animals (NIH Publications No. 8023, revised 1978) and in accordance with the recommendation of the proper care and use of laboratory animals, regulated by Faculty of Science, Tanta University, Tanta, Egypt. Then and there, mice were divided into eight groups ( $n=20 /$ group) whose description are shown later.

\section{Chemicals and reagents}

$\omega-3$ fatty acids were purchased from local Sigma Chemical Co. (St. Louis, MO). Olive oils were either purchased at a local market [extra virgin olive oil, or supplied commercially (refined, bleached, and deodorized olive oil)] (Beatrice/Hunt Wesson Co., Fullerton, CA). All other chemicals and organic solvents of analytical grade were obtained from local Egyptian companies. $\omega-3$ fatty acids stock solution was prepared by dissolving $\omega-3$ fatty acids in olive oil as required and stored in dark glass bottles at $4^{\circ} \mathrm{C}$ until use.

\section{Experimental design and treatments}

Mice were randomly divided into eight groups; $1^{\text {st }}, 2^{\text {nd }}, 3^{\text {rd }}$ and $4^{\text {th }}$ groups were designed to represent the short-term treatment protocol. The $1^{\text {st }}$ group received daily oral treatment with $200 \mu$ l olive oil vehicle as control. The $2^{\text {nd }}, 3^{\text {rd }}$ and $4^{\text {th }}$ groups were orally treated daily with 200 $\mu$ l olive oil containing at $10 \mu \mathrm{g}, 20 \mu \mathrm{g}$ and $30 \mu \mathrm{g} \omega$ - 
3 fatty acids, respectively for 1 month. The $5^{\text {th }}$, $6^{\text {th }}, 7^{\text {th }}$ and $8^{\text {th }}$ groups were designed to represent the long-term treatment protocol. The $5^{\text {th }}$ group received daily treatment with olive oil. The $6^{\text {th }}, 7^{\text {th }}$ and $8^{\text {th }}$ groups were orally treated with $200 \mu$ l olive oil containing $10 \mu \mathrm{g}$, $20 \mu \mathrm{g}$ and $30 \mu \mathrm{g} \omega-3$ fatty acids, respectively for 2 months. The oral treatment was given by gavage. The doses of $\omega-3$ fatty acids were calculated according to dose conversion from humans to animals according to the equivalent surface area dosage conversion factors from the table of Paget and Barnes (1964).

\section{Determination of the body weight changes}

The body weights of mice in all experimental groups were closely monitored during the treatment period using a digital balance. The body weight of mice was recorded as initial weight $\left(\mathrm{Wt}_{\mathrm{i}}\right)$ and final weight $\left(\mathrm{Wt}_{\mathrm{f}}\right)$, respectively. The percent of change in the body weights of mice during short and long treatment periods were calculated according to the following equation:

Weight \% change $=\left[\left\{\mathrm{Wt}_{\mathrm{f}}-\mathrm{Wt}_{\mathrm{i}}\right) / \mathrm{Wt}_{\mathrm{i}}\right] \times 100$

\section{Blood sampling and serum separation}

At the end of both short- and long-experiments, the mice fasted for $12 \mathrm{~h}$, and then anaesthetized with inhalation of isoflurane (1-chloro-2, 2, 2triflouoroethyl difluoromethyl ether; Hospira, Inc, Lake Forest, IL, USA). Two blood samples were collected from orbital venous plexus using microhematocrit capillary tubes. One blood sample was obtained in test tubes containing EDTA for complete blood count (CBC) and hemoglobin estimation. The other sample was obtained in non-heparinized plain tubes and allowed to clot at $37^{\circ} \mathrm{C}$ for 15 minutes and then centrifuged at $3000 \mathrm{rpm}$ for 15 minutes to separate sera. Sera were kept in aliquots and frozen for biochemical analysis as required.

\section{Estimation of complete blood count (CBC)}

Fresh blood samples were used for hematological analysis (using a Nihon Kohden automated hematology analyzer (model MEK$6318 \mathrm{~K}$, Japan), including red blood cell count (RBCs) $\left(10^{6} / \mu \mathrm{l}\right)$, hemoglobin concentrations ( $\mathrm{Hb}$ $\mathrm{g} / \mathrm{dl})$, hematocrit percentage (Hct\%), platelet count $\left(10^{3} / \mu \mathrm{l}\right)$. Additionally, white blood cells (WBCs) $\left(10^{3} / \mu \mathrm{l}\right)$ and their differential relative \% (neutrophils, lymphocyte, basophils, and monocytes) in were done.

\section{Determination of total serum cholesterol level}

Serum total cholesterol was determined according to the kit purchased from Bioscience (Cholesterol-Liquizyme). This method is based on CHOD-PAP-enzymatic colorimetric method, kit number (230002) according to the method of Allain et al. (1974). The principle of this involved approach based on the use of three enzymes; Cholesterol esterase (CE), cholesterol oxidase (CO) and peroxidase (POD). In the presence of the former mixture, phenol and 4aminoantipyrine (4-AA) are condensed by hydrogen peroxide to form a quinoneimine dye proportional to the concentration of cholesterol in the serum sample, which is quantitated spectrophotometric at $500-550 \mathrm{~nm}$.

\section{Determination of serum level of triglycerides}

The serum levels of triglycerides were determined according to the kit from Bioscience (triglycerides - Liquizyme). This method is based on GPO-PAP - enzymatic colorimetric method, kit number (314 002) based on the method of Fossati and Prenciple (1982). The principle of this method is based on the enzymatic hydrolysis of serum triglycerides to glycerol and free fatty acids (FFA) by lipoprotein lipase (LPL). The glycerol is phosphorylated by adenosine triphosphate (ATP) in the presence of glycerol kinase (GK) to form glycerol-3-phosphate (G-3$P)$ and adenosine diphosphate (ADP). G-3-P was oxidized by glycerol phosphate oxidase (GPO) to form dihydroxyacetone phosphate (DHAP) and hydrogen peroxide. A red color produced by the peroxidase (POD) catalyzed coupling of 4aminoantipyrine (4-AA) and phenol with hydrogen peroxide $\left(\mathrm{H}_{2} \mathrm{O}_{2}\right)$ is proportional to the concentration of triglycerides in the serum. Absorbance (A) of samples and standard were measured spectrophotometrically at $540 \mathrm{~nm}$ against the reagent blank within 30 minutes.

\section{Oxidation markers}

Sera were used to estimate markers of the oxidation process involving free radical scavenging enzymatic markers such as superoxide dismutase (SOD), and glutathione peroxidase (GPx) activity as well as and nonenzymatic agents such as reduced glutathione 
(GSH) and malondialdehyde (MDA) as an end product of peroxidation process.

\section{Reduced glutathione level}

Glutathione ( $\gamma$-glutamyl cysteinylglycine or GSH) is a naturally occurring tripeptide that is crucial to a variety of life processes including the detoxification of xenobiotics, maintenance of the-SH level in proteins, thiol-disulfide exchange, removal of hydroperoxides and free radicals, and amino acid transport across membranes. Glutathione level was estimated by the method of Ellman (1959) based on the oxidation of GSH by 5,5'-dithiobis-2nitrobenzoic acid [DTNB] to measure the reduced glutathione (GSH) content of biological samples. GSH reacts with DTNB to produce a yellow-colored 5-thiolo-2-nitrobenzoic acid (TNB) measured spectrometric at $412 \mathrm{~nm}$.

\section{Glutathione peroxidase activity}

Serum glutathione peroxidase, Gpx activity was measured by ELISA technique using a commercial kit (Rat AL033363 ELISA Kit). The assay procedure was carried out according to Sies (1997) instructions in the Manufacturer's booklet.

\section{Test principle}

The microliters plate has been pre-coated with an antibody specific to GPx-1. Then a biotinconjugated polyclonal antibody was added to the wells. Avidin conjugates to Horseradish Peroxidase (HRP) followed by TMB substrate solution are added to wells and incubated to exhibit color change which was measured at a wavelength of $450 \mathrm{~nm} \pm 2 \mathrm{~nm}$.

\section{Superoxide dismutase activity}

Serum superoxide dismutase activity (SOD; EC 1.15.1.1) was assayed by the method of Misra and Fridovich (1972). The principle of this method involves the inhibition of epinephrine auto-oxidation in an alkaline medium ( $p \mathrm{H}$ 10.2) to adrenochrome, which is markedly inhibited by the presence of SOD. Epinephrine was added to the assay mixture, containing serum and the change in extinction coefficient was followed at $480 \mathrm{~nm}$ in a spectrophotometer. The unit of enzyme activity is defined as the enzyme required for $50 \%$ inhibition of auto-oxidation of epinephrine.

\section{Calculation}

Inhibition $\%=[(\Delta \mathrm{A}$ Control $-\Delta \mathrm{A}$ Sample $) / \Delta \mathrm{A}$ Control $] 100$ Specific activity $(\mathrm{U} / \mathrm{mg}$ protein $)=\%$ inhibition $* 3.75 * 10$ / $\mathrm{mg}$ protein

Where:

$\Delta \mathrm{A}_{\text {control: }}$ Difference in control absorbance per minute.

$\Delta \mathrm{A}_{\text {sample: }}$ Difference in sample absorbance per minute.

Determination of malondialdehyde level

Malondialdehyde (MDA) as one of the terminal products, thiobarbituric acid reactive substances (TBARS) is formed at the time of the decomposition of polyunsaturated fatty acids mediated by free radicals. Estimation of MDA was carried out by the method of Placer et al. (1966). This method is based on the determination of MDA, an end product of lipid peroxidation, which can react with thiobarbituric acid (TBA) to yield a pink-colored complex, the intensity of this color is directly proportioned with the absorbance that expresses MDA concentration ( $\mathrm{nmol} / \mathrm{ml})$.

\section{Measurement of serum pituitary-thyroid hormones \\ Total $T_{3}$ and $T_{4}$ levels}

Assessment of total serum triiodothyronine $\left(T_{3}\right)$ and thyroxine $\left(T_{4}\right)$ levels was carried out according to Chopra et al. (1971) by ELISA assay using commercial kits of numbers (10301 and 10302) from Biocheck, Inc (USA). This ELISA test was determined by competitive enzyme immunoassay. The essential reagents required for a solid phase enzyme immunoassay included immobilized $1^{\text {st }}$ antibody $\left[T_{3} / T_{4}\right.$ mouse antibodies $(\mathrm{mAb})]$, enzyme- $2^{\text {nd }}$ antibody conjugate [anti- $T_{3} / T_{4}$-horseradish peroxidases (HRP)] and serum $T_{3} / T_{4}$. Upon mixing immobilized antibody, enzyme-antigen conjugate and a serum containing $T_{3} / T_{4}$, a competition reaction resulted between the serum $T_{3} / T_{4}$ and the enzyme $T_{3} / T_{4}$ conjugate for a limited number of insolubilized binding sites. Stop coloring reagent $\left(0.5 \mathrm{~N} \mathrm{H}_{2} \mathrm{SO}_{4}\right)$ was added to prevent color development. The enzyme activity in the antibody-bound fraction is inversely proportional to serum $T_{3} / T_{4}$ concentration.

\section{Thyroid-stimulating hormone or Thyrotropin}

Total thyrotropin (TSH) in the serum was ascertained according to Engall (1980) using kits of Biocheck, Inc (10304, USA). This assay is based on the principle of a solid-phase ELISA. 
This assay utilized a unique monoclonal antibody directed against a distinct antigenic determinant on the intact serum TSH molecule. Mouse monoclonal anti-TSH antibody was used for solid-phase immobilization. A goat anti-TSH antibody is the antibody-enzyme (TSHhorseradish peroxidase) conjugate solution. The test sample was allowed to react simultaneously with the two antibodies, resulting in the TSH molecule being sandwiched between the solid phase and enzyme-linked antibodies. A solution of tetramethylbenzidine (TMB) substrate was added and blue color was developed. The yellow color development was stopped by adding a stop solution ( $1 \mathrm{~N} \mathrm{HCL})$; the concentration of serum TSH is directly proportional to the color intensity of the test sample. Absorbance was measured at $450 \mathrm{~nm}$ by a spectrophotometer using a Dynix plate reader within 15 minutes of color development.

\section{RESULTS}

\section{Effect of $\omega-3$ fatty acids on the body weight of mice}

As shown in Table 1, the oral administration of mice with $\omega 3$ exhibited changes in body weight after both short- and long periods of administration. Post short-term, the body weight of mice decreased significantly after 10 , 20 and $30 \mu \mathrm{g} / \mathrm{kg} \omega-3$ FAs with percentages of change ranging from $-13.54 \%$ to $-17.55 \%$ compared to the control group. Also, these treatments of $\omega 3$ for a long term showed a further significant decrease with percentages ranging from $-10.8 \%$ to $-16.56 \%$ compared to the control group. However, the body weight reducing effect was dose-dependent than timedependent, $30 \mu \mathrm{g} / \mathrm{kg}$ dose of $\omega-3$ FAs was of a marked effect.

\section{Effect of $\omega-3$ fatty acids on the serum lipid profile}

Serum cholesterol: Results of the lipid profile including cholesterol (Chol) and triglycerides (TGs) in mice after treatment with three doses of $\omega 3$ are shown in Table 2 . The administration of mice with 10,20 and $30 \mu \mathrm{g} / \mathrm{kg}$ of $\omega-3$ FAs reduced the blood levels of the lipid components after short- and long-terms of administration. After short-term, the serum Chol levels were reduced significantly after 10,20 and $30 \mu \mathrm{g} / \mathrm{kg}$ of $\omega-3$ FAs with $-8.97 \%,-14.6 \%$ and $-15 \%$, respectively compared to the control group. In addition, such treatments of $\omega-3$ FAs showed a significant decrease with percentages of $-8.22 \%$, $-21.9 \%$ and $-28.36 \%$ after their administration for the long-term period. It was observed that these doses in the long-term had marked effects $(-8.22 \%$ to $-28.36 \%)$ compared to the short-term $(-8.27 \%$ to $-15 \%)$, respectively. In both periods, the $20 \mu \mathrm{g} / \mathrm{kg}$ and $30 \mu \mathrm{g} / \mathrm{kg} \omega-3$ FAs were more effective and had a more potent reducing effect compared to the control.

Serum triglycerides: Furthermore, Table 2 shows the effect of $\omega 3$ treatments on the serum TGs level after both periods; short and long. All dealings induced significant reductions in TGs levels with $-3.01 \%,-8.03 \%$ and $-9.7 \%$, respectively compared to the control group. Further significant decreases $-5.1 \%,-4.85 \%$ and $14.56 \%$, respectively compared to the control were obtained after $\omega-3$ FAs treatments to mice for the long term. Depicted results showed that treatments in the long-term had marked effects $(-5.01 \%$ to $-14.56 \%)$ compared to the short-term (-3.01\% to $-9.7 \%)$, respectively. Interestingly, the $30 \mu \mathrm{g} / \mathrm{kg}$ of $\omega-3$ FAs induced a decrease in TGs level after both periods with a prominent effect after the long term compared to control.

Effect of $\omega-3$ fatty acids on oxidant and antioxidant biomarkers: Data in Table 3 show the effects of $\omega-3$ FAs on oxidation biomarkers (GSH and MDA) and the activity of antioxidants (Gpx, SOD) in mice sera after short- and longterms of administration. After both treatment protocols, the activity of GPx and SOD were augmented while GSH was reduced and MDA was elevated. The ascending doses of $\omega-3$ FAs for both short and long treatments reduced GSH serum level as shown in Table 3. In both time intervals, all doses of $\omega-3$ FAs decreased significantly GSH with a striking reducing effect of $30 \mu \mathrm{g} / \mathrm{kg}$ followed by $20 \mu \mathrm{g} / \mathrm{kg}$ then $10 \mu \mathrm{g} / \mathrm{kg}$ of $\omega-3$ FAs. In this concern, the percentages of reduction in GSH levels were -31.86, -4.03 and 2.2 after dose regimen in the short-term; -36.64, -13.98 and -6.21 after a long time, respectively compared to the control mice. However, the reducing effects of gradient doses in the longterm were more prominent compared to those of short-term administration. 
It was apparent that $30 \mu \mathrm{g} / \mathrm{kg}$ of $\omega-3$ FAs have a potent diminishing effect compared to the control and other doses.

In addition, Table 3 shows the glutathione peroxidase (GPx) activity after short- and longterms of gradient doses of $\omega 3$ administration to mice. All doses (after short-term) caused a significant enriched activity of GPX in the order of $30 \mu \mathrm{g} / \mathrm{kg}>20 \mu \mathrm{g} / \mathrm{kg}>10 \mu \mathrm{g} / \mathrm{kg}$ of $\omega-3$ FAs with percentages of change reached 24.59, 15.3 and 6.01 , respectively. After long-term dosing, the previous ratios reached 58.06, 19.35 and 9.03, respectively compared to the control group. The enhanced effects of the upgrading doses of $\omega-3$ FAs after the long-term were higher than shortterm administration. In aspects, $20 \mu \mathrm{g} / \mathrm{kg}$ and $30 \mu \mathrm{g} / \mathrm{kg}$ of $\omega-3$ FAs led to a prominent increase in Gpx activity.

For superoxide dismutase (SOD) activity post short- and long-terms of $\omega-3$ Fas administration, all doses increased significantly SOD activity. These increases are graded as $30 \mu \mathrm{g} / \mathrm{kg}>$ $20 \mu \mathrm{g} / \mathrm{kg}>10 \mu \mathrm{g} / \mathrm{kg}$ of $\omega-3$ FAs with $24.09 \%$, $19.28 \%$ and $10.24 \%$, respectively after short administration. The same rank was obtained after long administration with percentages of (69.56, 28.98 and 14.49), respectively compared all to the control group. Considering the time of administration, the increased activity of SOD after the long-term was more elevated than in the short term. However, $30 \mu \mathrm{g} / \mathrm{kg}$ of $\omega-3$ FAs led to a marked increase in SOD activity in both periods.

In the contrary, MDA level was significantly increased after short-term of 10,20 and $30 \mu \mathrm{g} / \mathrm{kg}$ $\omega-3$ FAs $(3.05 \%, 15.23 \%$ and $15.8 \%)$, separately compared to the control group. Additionally, these percentages were further increased $(8.72 \%, 15.12 \%$ and $54.7 \%)$ after long-term $\omega-3$ FAs treatments. Increased MDA level in the longterm was higher than obtained in the shortterm. However, 20 and $30 \mu \mathrm{g} / \mathrm{kg}$ of $\omega-3$ FAs led to a marked increase in MDA level compared to other treatments.

\section{Effect of $\omega-3$ fatty acids on the pituitary- thyroid hormones}

The effects of climbing doses of $\omega-3$ FAs on the hormones of pituitary - thyroid axis in mice sera are shown in Table 4. These treatments increased significantly the serum levels of $\mathrm{T}_{3}$ and $\mathrm{T}_{4}$ and on the other hand, they reduced TSH significantly in a dose-time dependent manner. The three-dose levels; $10 \mu \mathrm{g} / \mathrm{kg}, 20 \mu \mathrm{g} / \mathrm{kg}$ and $30 \mu \mathrm{g} / \mathrm{kg}$ of $\omega-3$ FAs increased $T_{3}$ level after short and long $\omega$-3treatments to mice. Thus, the percentage of change after short treatments reached 15.7, 8.26 and 2.47, individually; after long treatments, they reached 54.7, 15.12 and 8.72 , respectively compared to the control group. It was shown that the longer administration time, the potent effect of the dose regain resulted; however, $30 \mu \mathrm{g} / \mathrm{kg}$ of $\omega-3$ FAs were more effective.

In addition, these treatment protocols of $\omega-3$ FAs led to increased levels of $T_{4}$ after both short and long periods as shown in Table 4. Consequently, the percentages of change after short treatment were $32.5 \%, 26.5 \%$ and $14.45 \%$, respectively and after long treatment were $35.7 \%, 21.43 \%$ and $14.28 \%$, respectively compared to the control level. In both cases, the $30 \mu \mathrm{g} / \mathrm{kg} \omega-3$ FAs were more effective than other doses.

On the other hand, the used treatments of $\omega-3$ FAs showed a significant reduction in TSH serum levels after both treatment terms (Table 4). After short-term of 10,20 and $30 \mu \mathrm{g} / \mathrm{kg}$ of $\omega-3$ FAs administration, the percentages of reduction were $-29.03 \%$ followed by $-19.35 \%$ then by -8.14 , respectively. The same outcomes were obtained after long administration, where a dose of $30 \mu \mathrm{g} / \mathrm{kg} \omega-3$ FAs was more effective with $-35.86 \%$ followed by $20 \mu \mathrm{g} / \mathrm{kg}$ with $-26.08 \%$ then $10 \mu \mathrm{g} / \mathrm{kg}$ with $-11.96 \%$, respectively compared all to the control mice. In both, the dose of $30 \mu \mathrm{g} / \mathrm{kg} \omega-3$ FAs had more potent effects than others and was higher after longterm.

\section{Effect of $\omega-3$ fatty acids on blood indices}

RBCs count: As shown in Table 5, the administration of mice with $\omega-3$ FAs mostly increased the RBCs count after both short- and long-terms of administration. After the treatment regimen, RBCs count of mice increased significantly with percentages reached $16.88 \%$ and $20.6 \%$ after both shortand long-term (higher \%), respectively compared to the control group. In this case, both $30 \mu \mathrm{g} / \mathrm{kg}$ and $20 \mu \mathrm{g} / \mathrm{kg}$ of $\omega-3$ FAs resulted 
in marked premier RBCs count after both periods.

Hemoglobin concentration: Increased hemoglobin concentrations $[\mathrm{Hb}]$ of mice were shown after $\omega-3$ FAs administration for shortand long-terms (Table 5). Treatment of mice with 10, 20 and $30 \mu \mathrm{g} / \mathrm{kg} \omega-3$ FAs for both periods increased [Hb] significantly with percentages reached $29.7 \%$ and $27.67 \%$, respectively compared to the control value of [Hb]. In both periods, the $30 \mu \mathrm{g} / \mathrm{kg}$ of $\omega-3$ FAs was more effective particularly after the longterm compared to the other doses $(15.8 \%$ \& $14.8 \%)$, and (8.9\%).

\section{DISCUSSION}

The obtained data suggest that $\omega-3$ FAs with its upgrading doses reduced the body weight of mice in a dose-time dependent manner. This result may limit weight gain in mice by reducing fat deposits around the internal organs. Partially, our results agree with outcomes of Lapillonne et al (2004) who showed weight loss after $\omega$-3 FAs supplementation and interpreted this weight loss to changes in gene expression in many tissues including liver, muscle, and adipose tissue, which was not measured in this work. In the same line, transgenic Fat-1 mice that are endogenously able to convert $\omega-6$ FAs into $\omega-3$ FAs, and rodents fed an enriched $\omega-3$ FAs diet were more resistant to weight gain, had decreased fat deposition, and higher energy expenditure. Moreover, these mice were also shown to have reduced inflammation through a marked attenuation of a transcription nuclear factor NF-KB activity (Mulhearn et al., 2019).

Consequently, individuals in the highest quartile of plasma $\omega-3$ FAs were more likely to be Chinese Americans, have a lower body mass index (BMI). They have higher fruit and vegetables but lower meat intakes; while those in the highest quartile of plasma $\omega-6$ FAs were younger, less physically active, and had lower consumption of whole grains, fish, fruit, and vegetables. Using the National Health and Nutrition Examination Survey (NHANES) data, Heymsfield et al. (2016) showed that for individuals with the same BMI and height, regional mass and body composition (e.g., fat, musculoskeletal and lean mass) differed between races/ethnicities, and the difference was stronger among young individuals. These findings support the concept that increasing levels of $\omega-3$ FAs in the body may represent an important strategy to counteract the development of weight gain and associated metabolic diseases.

The lipid profile means the lipid compartments of total cholesterol and triglycerides which are synthesized by the liver cells and released into the bloodstream. The level of these components affects the arterio-vascular system and liver especially if increased above normal value leading to hepatopathy, arteriosclerosis, hypertension and fatty liver. Therefore, estimation of the serum level of total Chol and TGs is indicative for the general health of mice.

In this concern, the dietary intake of EPA ( $\omega-3$ fatty acids metabolite) is effective in reducing fatty droplets by decreasing the formation of hepatic cholesterol, TG, and non-esterified fatty acids in high-fat diet-fed mice (Nemoto et al., , 2009). When mice were fed high sucrose/HFD supplemented with EPA, reduced $d$ galactosamine-induced hepatic injury as evidenced by a decreased hepatocyte necrosis and inflammatory cell infiltration. This result was also accompanied by lowered hepatic TG levels through the reduction of FAS and SCD-1 gene expression, decreased ROS production, and increased plasma adiponectin (Kajikawa et al., 2009). They added that EPA improved steatohepatitis by reducing steatosis lobular inflammation, and hepatocytes swelling and these effects could contribute to suppressing the progression of hepatitis.

Administration of $\omega-3$ FAs in ascending doses decreased the serum level of the lipid profile components including $\mathrm{Chol}$ and TGs. They were markedly reduced after treatment with high doses after both short and long periods; such effect was more potent after a long time. These results indicate that $\omega-3$ FAs make the intact hepatocytes healthier to be able to synthesize chymomicrones (proteins), which carry lipids to the liver to be excreted in the bile or to the kidney to be excreted in the urine. This observation gives us the ability to show why the serum lipid contents were reduced compared to the control. There is a great deal of evidence by many authors on the efficacy of $\omega-3$ FAs 
supplementation with similar effects on lipid metabolism. They have anti-inflammatory effects, reduced TGs, reduced insulin response to glucose, and reduced the risk of cardiovascular diseases and cancer (Jayasooriya et al., 2004; Leitzmann et al., 2004; Saldeen \& Saldeen, 2004). These effects of $\omega-3$ fatty acids are improved by aerobic exercise (Warner et al., 1989; Thomas et al., 2000), which is also advisable for subjects whose diet involves a high protein intake. In the same line, an animal study has shown that a diet with $\omega-3$ FAs usually lowered plasma TGs and total Chol levels almost always due to a decrease in HDL cholesterol (Harris, 1997).

In the same concern, Souza et al. (2010) showed that fish oils are known to reduce TG concentration by inhibiting hepatic VLDL-TG production and they hypothesized that $\omega-3$ FAs might reduce TG secretion from the intestine into the blood. Another study by Xin et al. (2012) stated that fish oil feeding did not slow TG absorption or chylomicron secretion in rats or secretion from rabbit enterocytes in vivo. Together, these data suggest that fish oils do not affect intestinal chylomicron assembly and secretion as they do hepatic VLDL gathering.

Current results revealed that antioxidant markers (SOD, GPx, associated with the oxidative end product (MDA) were elevated in the serum after the administration of mice with $\omega-3$ FAs upgrading dose regimen. On the contrary, the oxidative reactant (GSH) which is oxidized by GPx, limits the oxidation processes, was reduced significantly in the mice sera after such treatments. In the two aspects, the high dose was found to be more potent particularly in the period. These data suggest that the healthy hepatocytes maintain normal levels of anti-oxidative enzymes that accelerate oxidation pathways of lipids inside liver cells. Dislike, GSH was reduced as treatments with $\omega$ 3 FAs accelerate the oxidation process of GSH to its oxidized form GSSH; GPx is a limiting factor of this process. In addition, the elevation of MDA as one important oxidative end product revealed that antioxidant increased activity can promote MDA formation in the blood to a level beyond the renal threshold to expel this end product into the urine. Previous studies (Urso and Clarkson, 2003) showed that cells continuously produce free radicals such as ROS as a part of metabolic processes. It is wellknown, when free radicals are generated, they can attack PUFAs in the cell membrane such as arachidonic acid (AA). This leads to lipid peroxidation, which reduces the membrane fluidity, permeability and excitability, producing hydrocarbon gases and aldehydes such as MDA. These free radicals are neutralized by an elaborate antioxidant defense system consisting of enzymes and numerous nonenzymatic antioxidants, including vitamin $\mathrm{C}$ and glutathione. Exercise can also produce an imbalance between ROS formation and antioxidants, which is referred to as oxidative stress.

In the same line, the efficacy of different diets in counteracting oxidative stress can be tested, and MDA levels can be used as a marker of oxidative stress. In this regard, our results disagree with that of Urso and Clarkson, (2003) who showed reduced MDA, a plasma marker of oxidative damage to lipids and an important plasma marker. We and other investigators (Johnson et al., 2018) observed that the activity of GPx and SOD increased significantly and the levels of MDA decreased significantly, confirming $\omega-3$ FAs can reduce oxidative stress. In the same concern, dietary supplementation with $\omega-3$ FAs boosts the antioxidant system.

In the present work, thyroid hormones (THs) were secreted within normal levels based upon enhanced feedback regulation mechanisms. Thyroid, $T_{3}$ and $T_{4}$ were increased while TSH was decreased in the serum after the administration of mice with $\omega-3$ FAs for both time intervals in a dose-time way. Well established that THs are important modulators of lipid metabolism, and thus, hypothyroidism is associated with increased levels of serum TGs, cholesterol and LDL cholesterol and vice versa hyperthyroidism is associated with their decreased levels (Bolkiny et al., 2019). In the practice, $\omega-3$ FAs can shift energy substrates away from their storage as TGs, suppressing lipogenesis and promoting the utilization of free fatty acids as fuel by increasing lipase activity and $\beta$-oxidation in mitochondria and peroxisomes. The $\omega-3$ FAs metabolites (EPA and DHA) are also poor substrates for TG synthesizing enzymes, thus decreasing lipid levels. Other studies (Sadow et 
al., 2003, Faustino et al., 2011) showed the hypo-lipidemic effect of $\omega-3$ FAs is not completely understood, but it seems that it is mainly exerted via the activation of gene expression by up-regulation of nuclear transcription factors, such as PPAR $\alpha$ receptors in the liver, which indicates cross-talk between $\omega-3$ FAs and THs secretion pattern. It can be anticipated that supplementing the diet with $\omega-3$ FAs may also influence adipose tissue metabolism and/or accumulation of the tissue in experimental rats by affecting their THs metabolism. Moreover, activities of thyroid peroxidase (TPO) and/or of THs conjugating enzymes (e.g. iodothyronine glucuronyltransferase, UDP-GT) may be modified by $\omega-3$ fatty acids supplementation and therefore the rate of biosynthesis and excretion of THs metabolites can be altered (Pavelka, 2010).

Table 1. Effect of the $\omega-3$ fatty acids oral administration on the body weight of mice after both short- and long-periods

\begin{tabular}{|c|c|c|c|c|c|c|}
\hline \multirow[b]{2}{*}{ Experimental groups } & \multicolumn{3}{|c|}{ Short-term treatment } & \multicolumn{3}{|c|}{ Long-term treatment } \\
\hline & $\mathrm{Wt}_{0}(\mathrm{X} \pm \mathrm{SD})$ & $W t_{f}(X \pm S D)$ & Change \% & $W_{t}(X \pm S D)$ & $W t_{f}(X \pm S D)$ & Change \% \\
\hline Olive oil $(200 \mu \mathrm{l})$ & $22.7 \pm 1.6$ & $34.1 \pm 1.1$ & - & $22.4 \pm 1.04$ & $34.4 \pm 0.9$ & - \\
\hline $10 \mu \mathrm{g} / \mathrm{kg} \omega-3 \mathrm{FAs}$ & $22.8 \pm 1.2$ & $32.7 \pm 1.1^{*}$ & -13.54 & $22.6 \pm 1.17$ & $33.2 \pm 1.1^{*}$ & -12.45 \\
\hline $20 \mu \mathrm{g} / \mathrm{kg} \omega-3$ FAs & $23.4 \pm 1.2$ & $33.1 \pm 0.9^{*}$ & -17.46 & $22.6 \pm 0.6$ & $33.4 \pm 1.2^{*}$ & -10.8 \\
\hline $30 \mu \mathrm{g} / \mathrm{kg} \omega-3$ FAs & $22.4 \pm 1.8$ & $31.9 \pm 0.6^{*}$ & -15.55 & $21.7 \pm 1.05$ & $31.4 \pm 0.9 *$ & -16.56 \\
\hline
\end{tabular}

Data are represented as mean $(\mathrm{X} \pm \mathrm{SD}), \mathrm{n}=5$. The change $\%$ means the difference ratio between $\mathrm{Wt}_{\mathrm{f}}-\mathrm{Wt}_{0}$ related to the control value. * Significant mean at $\mathrm{P} \leq 0.05$ versus control at the same period.

Table 2. Effect of $\omega-3$ fatty acids on lipid components in mice sera after both short- and long-terms of oral administration

\begin{tabular}{|c|c|c|c|c|c|}
\hline \multirow{2}{*}{ Mice groups } & \multirow{2}{*}{$\begin{array}{l}\text { Parameters } \\
\text { (unit) }\end{array}$} & \multicolumn{2}{|c|}{ Short-term treatment } & \multicolumn{2}{|c|}{ Long - term treatment } \\
\hline & & $(X \pm S D)$ & $\%$ & $(X \pm S D)$ & $\%$ \\
\hline Olive oil $(200 \mu \mathrm{l})$ & \multirow{4}{*}{$\begin{array}{c}\text { Cholesterol } \\
\text { (mg/dL) }\end{array}$} & $78 \pm 1$ & - & $73 \pm 1$ & - \\
\hline $10 \mu \mathrm{g} / \mathrm{kg} \omega-3$ FAs & & $71 \pm 1^{*}$ & -8.97 & $67 \pm 1.5^{*}$ & -8.22 \\
\hline $20 \mu \mathrm{g} / \mathrm{kg} \omega-3$ FAs & & $66.6 \pm 2^{*}$ & -14.6 & $57 \pm 1^{*}$ & -21.9 \\
\hline $30 \mu \mathrm{g} / \mathrm{kg} \omega-3$ FAs & & $66.3 \pm 1.2^{*}$ & -15 & $52.3 \pm 1 . * 5$ & -28.36 \\
\hline Olive oil $(200 \mu \mathrm{l})$ & \multirow{4}{*}{$\begin{array}{c}\text { Triglycerides } \\
\text { (mg/dL) }\end{array}$} & $119.6 \pm 1.5$ & - & $103 \pm 1.5$ & - \\
\hline $10 \mu \mathrm{g} / \mathrm{kg} \omega-3$ FAs & & $116 \pm 2$ & -3.01 & $98 \pm 1.15^{*}$ & -5.1 \\
\hline $20 \mu \mathrm{g} / \mathrm{kg} \omega-3$ FAs & & $110 \pm .57^{*}$ & -8.03 & $98 \pm 1.15^{*}$ & -4.85 \\
\hline $30 \mu \mathrm{g} / \mathrm{kg} \omega-3 \mathrm{FAs}$ & & $108 \pm 1.5^{*}$ & -9.7 & $88 \pm 1.5^{*}$ & -14.56 \\
\hline
\end{tabular}

Data are represented as means $(X \pm S D), n=5 \%$ means the percentage of change compared to the control group. ${ }^{*}$ Significant mean at $P \leq 0.05$ versus control of the same period.

Table 3. Effect of $\omega-3$ fatty acids on oxidant and antioxidant biomarkers after short- and long-terms of oral administration.

\begin{tabular}{|c|c|c|c|c|c|}
\hline \multirow{2}{*}{ Mice groups } & \multirow{2}{*}{$\begin{array}{l}\text { Parameters } \\
\text { (unit) }\end{array}$} & \multicolumn{2}{|c|}{ Short-term treatment } & \multicolumn{2}{|c|}{ Long-term treatment } \\
\hline & & $(X \pm S D)$ & $\%$ & $(X \pm S D)$ & $\%$ \\
\hline Olive oil $(200 \mu \mathrm{l})$ & \multirow[t]{4}{*}{ GSH (ng/ml) } & $0.273 \pm 0.002$ & - & $0.322 \pm 0.001$ & - \\
\hline $10 \mu \mathrm{g} / \mathrm{kg} \omega-3$ FAs & & $0.267 \pm 0.002^{*}$ & -2.2 & $0.302 \pm 0.001^{*}$ & -6.2 \\
\hline $20 \mu \mathrm{g} / \mathrm{kg} \omega-3 \mathrm{FAs}$ & & $0.262 \pm 0.001^{*}$ & -4.03 & $0.277 \pm 0.001 *$ & -13.98 \\
\hline $30 \mu \mathrm{g} / \mathrm{kg} \omega-3$ FAs & & $0.186 \pm 0.005^{*}$ & -31.86 & $0.204 \pm 0.001^{*}$ & -36.64 \\
\hline Olive oil $(200 \mu l)$ & \multirow[t]{4}{*}{$\mathrm{Gpx}(\mathrm{U} / \mathrm{L})$} & $0.183 \pm 0.001$ & - & $0.155 \pm 0.001$ & - \\
\hline $10 \mu \mathrm{g} / \mathrm{kg} \omega-3$ FAs & & $0.194 \pm 0.001^{*}$ & 6.01 & $0.169 \pm 0.001 *$ & 9.03 \\
\hline $20 \mu \mathrm{g} / \mathrm{kg} \omega-3 \mathrm{FAs}$ & & $0.211 \pm 0.001^{*}$ & 15.3 & $0.185 \pm 0.002^{*}$ & 19.35 \\
\hline $30 \mu \mathrm{g} / \mathrm{kg} \omega-3$ FAs & & $0.228 \pm 0.001^{*}$ & 24.59 & $0.245 \pm 0.017^{*}$ & 58.06 \\
\hline Olive oil $(200 \mu l)$ & \multirow[t]{4}{*}{ SOD (U/L) } & $0.166 \pm 0.001$ & - & $0.138 \pm 0.001$ & - \\
\hline $10 \mu \mathrm{g} / \mathrm{kg} \omega-3$ FAs & & $0.183 \pm 0.001^{*}$ & 10.24 & $0.158 \pm 0.001^{*}$ & 14.49 \\
\hline $20 \mu \mathrm{g} / \mathrm{kg} \omega-3 \mathrm{FAs}$ & & $0.198 \pm 0.001^{*}$ & 19.27 & $0.178 \pm 0.001^{*}$ & 28.98 \\
\hline $30 \mu \mathrm{g} / \mathrm{kg} \omega-3$ FAs & & $0.206 \pm 0.005^{*}$ & 24.09 & $0.234 \pm 0.001^{*}$ & 69.56 \\
\hline Olive oil $(200 \mu \mathrm{l})$ & \multirow[t]{4}{*}{$\mathrm{MDA}(\mathrm{nmol} / \mathrm{ml})$} & $0.197 \pm 0.001$ & - & $0.172 \pm 0.001$ & - \\
\hline $10 \mu \mathrm{g} / \mathrm{kg} \omega-3$ FAs & & $0.203 \pm 0.002$ & 3.05 & $0.187 \pm 0.001^{*}$ & 8.72 \\
\hline $20 \mu \mathrm{g} / \mathrm{kg} \omega-3 \mathrm{FAs}$ & & $0.227 \pm 0.003^{*}$ & 15.23 & $0.198 \pm 0.001^{*}$ & 15.12 \\
\hline $30 \mu \mathrm{g} / \mathrm{kg} \omega-3$ FAs & & $0.236 \pm 0.011^{*}$ & 19.79 & $0.266 \pm 0.001^{*}$ & 54.65 \\
\hline
\end{tabular}

Data are represented as means $(X \pm S D), n=5 \%$ means the percentage of change compared to the control group. ${ }^{*}$ Significant mean at $P \leq 0.05$ versus control of the same period. 
Table 4. Effect of $\omega-3$ fatty acids treatments on the serum pituitary-thyroid hormones in mice after short- and long- terms of oral administration

\begin{tabular}{|c|c|c|c|c|c|}
\hline \multirow{2}{*}{ Mice groups } & \multirow{2}{*}{$\begin{array}{c}\text { Hormone } \\
\text { (unit) }\end{array}$} & \multicolumn{2}{|c|}{ Short-term treatment } & \multicolumn{2}{|c|}{ Long-term treatment } \\
\hline & & $(X \pm S D)$ & $\%$ & $(X \pm S D)$ & $\%$ \\
\hline Olive oil $(200 \mu \mathrm{l})$ & \multirow{4}{*}{$T_{3} U / L$} & $1.21 \pm 0.02$ & - & $0.68 \pm 0.02$ & - \\
\hline $10 \mu \mathrm{g} / \mathrm{kg} \omega-3 \mathrm{FAs}$ & & $1.24 \pm 0.09$ & 2.48 & $0.75 \pm 0.03$ & 10.29 \\
\hline $20 \mu \mathrm{g} / \mathrm{kg} \omega-3 \mathrm{FAs}$ & & $1.31 \pm 0.02 *$ & 8.26 & $0.82 \pm 0.015^{*}$ & 20.58 \\
\hline $30 \mu \mathrm{g} / \mathrm{kg} \omega-3 \mathrm{FAs}$ & & $1.4 \pm 0.01^{*}$ & 15.7 & $0.95 \pm 0.02 *$ & 39.7 \\
\hline Olive oil $(200 \mu \mathrm{l})$ & \multirow[t]{4}{*}{$\mathrm{T}_{4} \mathrm{U} / \mathrm{L}$} & $1.66 \pm 0.06$ & - & $1.4 \pm 0.04$ & - \\
\hline $10 \mu \mathrm{g} / \mathrm{kg} \omega-3$ FAs & & $1.9 \pm 0.01 *$ & 14.46 & $1.6 \pm 0.06$ & 14.28 \\
\hline $20 \mu \mathrm{g} / \mathrm{kg} \omega-3 \mathrm{FAs}$ & & $2.10 \pm 0.1^{*}$ & 26.5 & $1.7 \pm 0.09$ & 21.43 \\
\hline $30 \mu \mathrm{g} / \mathrm{kg} \omega-3$ FAs & & $2.2 \pm 0.01^{*}$ & 32.5 & $1.9 \pm 0.04$ & 35.7 \\
\hline Olive oil $(200 \mu \mathrm{l})$ & \multirow[t]{4}{*}{ TSH U/L } & $0.93 \pm 0.04$ & - & $0.92 \pm 0.04$ & - \\
\hline $10 \mu \mathrm{g} / \mathrm{kg} \omega-3 \mathrm{FAs}$ & & $0.86 \pm 0.03 *$ & -7.5 & $0.81 \pm 0.025^{*}$ & -11.9 \\
\hline $20 \mu \mathrm{g} / \mathrm{kg} \omega-3 \mathrm{FAs}$ & & $0.66 \pm 0.02 *$ & -29 & $0.68 \pm 0.02 *$ & -26 \\
\hline $30 \mu \mathrm{g} / \mathrm{kg} \omega-3 \mathrm{FAs}$ & & $0.75 \pm 0.02 *$ & -19.4 & $0.59 \pm 0.04^{*}$ & -35.7 \\
\hline
\end{tabular}

Data are represented as means $(X \pm S D), n=5 \%$ means the percentage of change compared to the control group. ${ }^{*}$ Significant mean at $P \leq 0.05$ versus control of the same period.

Table 5. Blood indices, RBCs count and hemoglobin concentration in mice after both short- and long- terms of $\omega-3$ fatty acids oral administration.

\begin{tabular}{|l|c|c|c|c|c|}
\hline \multirow{2}{*}{ Mice groups } & Parameters & \multicolumn{2}{|c|}{ Short-term treatment } & \multicolumn{2}{c|}{ Long-term treatment } \\
\cline { 1 - 5 } & & X \pm SD & $\%$ & \multicolumn{1}{|c|}{ X \pm SD } & $\%$ \\
\hline Olive oil $(200 \mu \mathrm{l})$ & RBCs $/ \mathrm{mm}^{3}$ & $7.7 \pm 1.8$ & - & $7.96 \pm 0.9$ & - \\
\hline $10 \mu \mathrm{g} / \mathrm{kg} \omega$-3 FAs & & $7.6 \pm 0.4$ & -1.29 & $7.2 \pm 0.7^{*}$ & -9.55 \\
\hline $20 \mu \mathrm{g} / \mathrm{kg} \omega$-3 FAs & & $9 \pm 0.5^{*}$ & 16.88 & $8.5 \pm 0.3^{*}$ & 6.78 \\
\hline $30 \mu \mathrm{g} / \mathrm{kg} \omega$-3 FAs & & $8.9 \pm 0.7^{*}$ & 15.58 & $9.6 \pm 0.4^{*}$ & 20.6 \\
\hline Olive oil $(200 \mu \mathrm{l})$ & \multirow{2}{*}{$\mathrm{Hb} \mathrm{g} / \mathrm{dL}$} & $10.1 \pm 0.1$ & - & $11.2 \pm 0.2$ & - \\
\hline $10 \mu \mathrm{g} / \mathrm{kg} \omega$-3 FAs & & $11.7 \pm 0.4$ & 15.8 & $12.2 \pm 0.4$ & 8.96 \\
\hline $20 \mu \mathrm{g} / \mathrm{kg} \omega$-3 FAs & & $11.6 \pm 0.3$ & 14.8 & $12.2 \pm 0.2$ & 8.96 \\
\hline $30 \mu \mathrm{g} / \mathrm{kg} \omega$-3 FAs & & $13.1 \pm 0.5$ & 29.7 & $14.3 \pm 0.3$ & 27.67 \\
\hline
\end{tabular}

Data are represented as means $(X \pm S D), n=5 \%$ means the percentage of change compared to the control group. ${ }^{*}$ Significant mean at $P \leq 0.05$ versus control of the same period.

Furthermore, $\omega-3$ FAs have been shown to build up TH signaling (may then ameliorate such negative effects). Souza et al. (2011) observed the enhancement of not only TRb1 protein content and mGPD activity but also their respective mRNAs, suggesting the involvement of a transcriptional mechanism. This consistent induction of TRb1 expression suggests a role for TH signaling in the $\omega-3$ FAs effects on hepatic metabolism, given the well-known hypolipidemic actions of TH, mediated by TRb1 isoform (Gullberg et al. 2002, Johansson et al. 2005, and Hashimoto et al. 2006). Therefore, these data suggest that $\omega-3$ FAs are able not only to increase TRb1 expression but also to enhance TH signaling at specific targets (Sadow et al., 2003, Faustino et al., 2011). They added that the ability of $\omega-3$ FAs to enhance both TRb1 liver expression and its target MGPD was lost in hypothyroidism, along with the abolition of $\omega-3$ FAs effects on serum TGs and body lipid content, but conservation of cholesterollowering effect of such fatty acids. Thus, our data are in agreement with previous results and suggest that $\omega-3$ FAs effects on lipid metabolism are dependent on THs signaling, at least, in specific steps. $\omega-3$ FAs including EPA regulates the thyroid cell functions via two main pathways: regulation of signal transduction mechanism by manipulating the composition of membrane fatty acids; and the second pathway through rapid and direct modulation of gene transcription mechanism (Qazzaz et al., 2020).

Our results of $C B C$ showed that the high therapeutic dose of $\omega-3$ FAs increased the RBCs count and the $\mathrm{Hb}$ concentration than other dose regimens, which caused minor changes more or less than the therapeutic dose. In this aspect, the cell membrane of RBCs contains a bilayer of phospholipid containing $\omega-3$ FAs of a wide range of beneficial properties. 
An increased number of reports demonstrated that DHA-containing phospholipids can influence the cell membrane properties such as permeability, fusion, and plane elasticity (Stillwell and Wassal, 2003; Rizzo et al, 2010). An in vivo study with animal models have indicated that PUFAs affect membrane lipid composition, blood lipid profiles, eicosanoids biosynthesis, cell signaling cascades, gene expression and the functioning of the cardiovascular system; they are involved in amending or preventing the etiology of several different pathologies (Stillwell et al., 2005).

Supplementation of patients with homozygous sickle cell disease (HbSS) with $\omega-3$ FAs metabolites (DHA and EPA) was effective in reducing the frequency and severity of vasoocclusive episodes, severe anemia, and blood transfusion rate. These beneficial effects were reflected in noticeable improvements in health and related quality of life as evaluated by significant reductions in the number of inpatient hospital days and improvements in school absence due to HbSS-related illness. However, the synergistic effects of decreased inflammation, blood cell aggregation, adhesion, and oxidative stress and increased vasodilatation and blood flow (Mayer et al., 2002; Ruxton et al., 2005) may have a critical role in the amelioration of vaso-occlusive and hemolytic crises in the above-mentioned patients. In addition, $\omega$-3 FAs can be effective, safe, and affordable as a treatment for sickle cell anemia (Daak et al., 2013; 2020) due to Lipoxygenase products of the $\omega-3$ FAs, docosahexaenoic (DHA) and eicosapentaenoic (EPA) acids are potent anti-inflammatory mediators modulating pain. Settya et al. (2019) showed that the $\omega-3$ FAs administration decreased episodes of vaso-occlusion in sickle cell disease (SCD). In the same regard, experimental and clinical studies provide evidence that treatment with DHA does confer improvement properties of sickle RBC, inflammation and hemolysis. It can be concluded that the results of this study in collaboration with previous studies may confirm that the administration of $\omega-3$ FAs in high doses for a longer time provides good evidence for health promotion through reducing body weight, blood lipid components, oxidative stress and CBC enhancement.

\section{CONFLICTS OF INTEREST}

All authors declare no conflicts of interest.

\section{FUND}

No fund was received for this work.

\section{References}

Allain CC, Poon LS, Chan CG, Richmond W, Fu PC (1974). Enzymatic determination of total serum cholesterol. Clinical Chemistry, 20: 470-475.

Bolkiny YE, Tousson E, El-Atrsh A, Akela M, Farg E. (2019) Costus Root Extract Alleviates Blood Biochemical Derangements of Experimentally-Induced Hypo-and Hyperthyroidism in Mice. Annual Research \& Review in Biology, 31(5):1-0.

Bolles KL, Begg GA (2000). Distinction between silver hake (Merluccius bilinearis) stocks in US waters of the northwest Atlantic based on whole otolith morphometrics. Fish Bulletin 98: 451-462.

Bousquet M., Saint-Pierre M., Julien C., Salem Jr, N., Cicchetti F., Calon F. (2008). Beneficial effects of dietary $\omega-3$ polyunsaturated fatty acid on toxin-induced neuronal degeneration in an animal model of Parkinson's disease. The FASEB Journal, 22(4): 1213-1225.

Burlingame, B., Nishida, C., Uauy, R., Weisell, R. (2009). Fats and fatty acids in human nutrition: introduction. Annals of Nutrition and Metabolism, 55(1-3): 5-7.

Calder P. C., Ahluwalia N., Brouns F., Buetler T., (2011). Dietary factors and low-grade inflammation in relation to overweight and obesity. British Journal of Nutrition , 106 (3), S5-S78.

Chapkin, R.S., Kim, W., Lupton, J. R., McMurray, D.N. (2009). Dietary docosahexaenoic and eicosapentaenoic acid: emerging mediators of inflammation. Prostaglandins, Leukotrienes and Essential Fatty Acids, 81(23): 187-191.

Chopra IJ, Nelson JC, Solomon DH, Beall GN (1971). Production of antibodies specifically binding triiodothyronine and thyroxine. I Clininical Endocrinology and Metabolism, 32(3): 299308.

Cockbain, A.J., Toogood, G. J., Hull, M.A. (2012). Omega-3 polyunsaturated fatty acids for the treatment and prevention of colorectal cancer. Gut, 61(1): 135-149. 
Daak A., Ghebremeskel K., Hassan Z., Attallah B., Azan H., Elbashir M., Crawford M. (2013). Effect of $\omega-3$ fatty acid supplementation in patients with sickle cell anemia: randomized, double-blind, placebo-controlled trial. The American Journal of Clinical Nutrition, 97(1): 37-44.

Daak A., Lopez-Toledano MA., Heeney MM. (2020). Biochemical and therapeutic effects of $\Omega-3$ fatty acids in sickle cell disease Author links open overlay pane. Elsevier (Complementary therapies in medicine).52: 102482

Ellman GL (1959) Tissue sulfhydryl groups. Archive Bioiological chemistry Biophysics 82 : 70-77.

Engall $E$ (1980): Methods in Enzymology .Van Vunakis H, Langone JJ (eds.). Academic Press, New York. Pp. 419-492.

Faustino, L.C., Pires, R.M., Lima, A.C., Cordeiro, A., Souza, L.L., Ortiga-Carvalho, T.M. (2011). Liver glutathione S-transferase $\alpha$ expression is decreased by 3, 5, 3'-triiodothyronine in hypothyroid but not in euthyroid mice. Experimental physiology, 96(8): 790-800.

Fossati RM, Prenciple L (1982) Serum triglycerides determined colorimetrically with an enzyme that produces hydrogen peroxide. Clininical Chemistry 28: 2077-2080.

Gullberg, H., Rudling, M., Saltó, C., Forrest, D., Angelin, B., Vennström, B. (2002). Requirement for thyroid hormone receptor $\beta$ in T3 regulation of cholesterol metabolism in mice. Molecular Endocrinology, 16(8): 17671777.

Harris W. S. (1997). n-3 fatty acids and serum lipoproteins: animal studies. The American journal of clinical nutrition, 65(5): 1611S$1616 \mathrm{~S}$.

Hashimoto, K., Cohen, R. N., Yamada, M., Markan, K. R., Monden, T., Satoh, T., Wondisford, F. E. (2006). Cross-talk between thyroid hormone receptor and liver $\mathrm{X}$ receptor regulatory pathways is revealed in a thyroid hormone resistance mouse model. Journal of Biological Chemistry, 281(1): 295-302.

Heymsfield, S. B., Peterson, C. M., Thomas, D. M., Heo, M., Schuna Jr, J. M. (2016). Why are there race/ethnic differences in adult body mass index-adiposity relationships? A quantitative critical review. Obesity Reviews, 17(3): 262-275.

Jayasooriya A.P., Weisinger R.S., Weisinger H.S., Mathai M., Puskas M., Kitajka K. Sinclair A.J. (2004). Dietary $\omega-3$ fatty acid supply influences mechanisms controlling body weight and glucose metabolism. Asia Pacific Journal of Clinical Nutrition, 13.
Johansson, L., Rudling, M., Scanlan, T. S., Lundåsen, T., Webb, P., Baxter, J, Parini, P. (2005). Selective thyroid receptor modulation by GC1 reduces serum lipids and stimulates steps of reverse cholesterol transport in euthyroid mice. Proceedings of the National Academy of Sciences, 102(29): 10297-10302.

Johnson W., Luqman A., and Olayaki A. (2018). Diclofenac - induced hepatotoxicity: Low dose of $\omega-3$ fatty acids have more protective effects. Elsevier, (Toxicology Reports) https://doi.org/10.1016/j.toxrep.2017.12.00 2

Kajikawa S., Harada T., Kawashima A., Imada K., Mizuguchi K. (2009). Suppression of hepatic fat accumulation by highly purified eicosapentaenoic acid prevents the progression of d-galactosamine-induced hepatitis in mice fed with a high-fat/highsucrose diet. Biochimica et Biophysica Acta (BBA)-Molecular and Cell Biology of Lipids, 1791(4): 281-288.

Kaur N., Chugh V., Gupta A.K. (2014). Essential fatty acids as functional components of foods, areview Journal of Food Science and Technology, 10: 2289-2303.

Lapillonne, A., Clarke, S. D., Heird, W. C. (2004). Polyunsaturated fatty acids and gene expression. Current Opinion in Clinical Nutrition \& Metabolic Care, 7(2): 151-156.

Leitzmann M.F., Stampfer M.J., Michaud, D.S., Augustsson K., Colditz G.C., Willett W.C., Giovannucci E.L. (2004). Dietary intake of n3 and $n-6$ fatty acids and the risk of prostate cancer. The American Journal of clinical Nutrition, 80(1): 204-216.

Mayer K, Merfels M, Muhly-Reinholz M, Gokorsch S, Rosseau S, Lohmeyer J, Schwarzer N, Krüll M, Suttorp N, Grimminger F et al., (2002). $\omega-3$ fatty acids suppress monocyte adhesion to human endothelial cells: role of endothelial PAF generation. Am J Physiol. Heart Circ. Physiol., 283: H811-8.

Miles, E. A., Calder, P. C. (2012). Influence of marine $\mathrm{n}-3$ polyunsaturated fatty acids on immune function and a systematic review of their effects on clinical outcomes in rheumatoid arthritis. British Journal of Nutrition, 107(S2): S171-S184.

Misra HP, Fridovich I (1972). The role of superoxide anion in the auto-oxidation of epinephrine and a simple assay for superoxidedismutase. Journal of Biological Chemsitry, 247: 3170 - 3175.

Mulhearn DS, Adhikari S, Cuesta SM, Antonio MD, Erard N, Hannon GJ, Tannahill D, Shankar Balasubramanian S. (2019). Genetic 
interactions of G-quadruplexes in humans. elife, 8: e46793.

Nemoto N., Suzuki S., Kikuchi H., Okabe H., Sassa S., Sakamoto S. (2009). Ethyl-eicosapentaenoic acid reduces liver lipids and lowers plasma levels of lipids in mice fed a high-fat diet. In vivo, 23(5): 685-689.

NIH (1978). Guidelines for the Care and Use of Laboratory Animals. NIH Guide - 7:(18).

Paget GE, Barnes JM (1964). Evaluation of drug activities. In: Lawrence DR, Bacharach AL (eds). Pharmacometrics. Vol. 1. New York, Academic Press, p 161.

Pavelka S (2010). Radiometric enzyme assays: development of methods for extremely sensitive determination of types 1,2 and 3 iodothyronine deiodinase enzyme activities. Journal of Radioanalytical and Nuclear Chemistry, 286(3): 861-865.

Placer ZA, Cushmann LL, Johnson BC (1966) Estimation of products of lipid peroxidation in biochemical systems. Anal Biochemistry 16: 359-364.

Qazzaz M., Alfahad M., Alassaf F., Abed M., Jasim M., and Thanoon I. (2020). Effects of $\omega-3$ on thyroid function tests in healthy volunteers. Sys Rev Pharm, 11(7):10-14A

Rizzo M, Montorfano G., Nagroni M., Adorni L., et al., (2010). Lipids in Health and Disease, 9:7.

Ruxton CH, Calder PC, Reed SC, Simpson MJ. (2005). The impact of long-chain $n-3$ polyunsaturated fatty acids on human health. Nutrition Research Review, 18:113-29.

Sadow, P. M., Chassande, O., Gauthier, K., Samarut, J., Xu, J., O' Malley, B. W., Weiss, R. E. (2003). Specificity of thyroid hormone receptor subtype and steroid receptor coactivator-1 on thyroid hormone action. American Journal of Physiology-Endocrinology and Metabolism, 284(1): E36-E46.

Saldeen P., and Saldeen T. (2004). Women and $\omega-3$ Fatty acids. Obstetrical \& gynecological survey, 59(10): 722-730.

Settya BN, Betal SG, Dawn RE, Brown S, Meier M, et al. (2019). Relationship of $\omega-3$ fatty acids DHA and EPA with the inflammatory biomarker hsCRP in children with sickle cell anemia. Elsevier (Iprostaglandins, leukotrienes and Essential fatty aids), 146:11-18.
Sies, H. (1997). Oxidative stress oxidants and antioxidants. Experimental Physiology, 82 (2):291-295.

Souza, L. L., Cordeiro, A., Oliveira, L. S., Paula, G. S. M. D., Faustino, L.C., Ortiga-Carvalho, T.M., Pazos-Moura, C.C. (2011). Thyroid hormone contributes to the hypolipidemic effect of polyunsaturated fatty acids from fish oil: in vivo evidence for cross talking mechanisms. Journal of endocrinology, 211(1): 65.

Souza, L.L., Nunes, M.O., Paula, G.S., Cordeiro, A., Penha-Pinto, V., Neto, J. F. N., Pazos-Moura, C.C. (2010). Effects of dietary fish oil on thyroid hormone signaling in the liver. The Journal of Nutritional Biochemistry, 21(10): 935-940.

Stillwell W. and Wassall S. R. (2003). Docosahexaenoic acid: membrane properties of a unique fatty acid. Chemistry and Physics of Lipids, 126(1): 1-27.

Stillwell W., Shaikh S. R., Zerouga M., Siddiqui R., Wassall S. R. (2005). Docosahexaenoic acid affects cell signaling by altering lipid rafts. Reproduction Nutrition Development, 45(5): 559-579.

Thomas T.R., Fischer B.A., Kist W.B., Horner K.E., Cox R.H. (2000). Effects of exercise and n-3 fatty acids on postprandial lipemia. Journal of Applied Physiology, 88(6): 2199-2204.

Urso M.L. and Clarkson P.M. (2003). Oxidative stress, exercise, and antioxidant supplementation. Toxicology, 189(1-2): 41-54.

Vaughan, V. C., Hassing, M. R., Lewandowski, P. A. (2013). Marine polyunsaturated fatty acids and cancer therapy. British Journal of Cancer, 108(3): 486-492.

Warner Jr J. G., Ullrich I.H., Albrink M. J., Yeater R.A. (1989). Combined effects of aerobic exercise and $\omega-3$ fatty acids in hyperlipidemic persons. Medicine and science in sports and exercise, 21(5): 498-505.

Xin, W., Wei, W., Li, X. (2012). Effects of fish oil supplementation on cardiac function in chronic heart failure: a meta-analysis of randomised controlled trials. Heart, 98(22): 1620-1625. 